\title{
Extracellular vesicles and reproduction-promotion of successful pregnancy
}

\author{
Dionne Tannetta, Rebecca Dragovic, Zahraa Alyahyaei and Jennifer Southcombe
}

Extracellular vesicles (EVs) are membrane-bound complexes secreted from cells under both physiological and pathological conditions. They contain proteins, nucleic acids and lipids and act as messengers for cell-cell communication and signalling, particularly between immune cells. EV research is a rapidly evolving and expanding field, and it appears that all biological fluids contain very large numbers of EVs; they are produced from all cells that have been studied to date, and are known to have roles in several reproductive processes. This review analyses the evidence for the role of EVs throughout human reproduction, starting with the paternal and maternal gametes, followed by the establishment and continuation of successful pregnancies, with specific focus, where possible, on the interaction of EVs with the maternal immune system. Importantly, variations within the EV populations are identified in various reproductive disorders, such as pre-term labour and pre-eclampsia.

Cellular \& Molecular Immunology (2014) 11, 548-563; doi:10.1038/cmi.2014.42; published online 23 June 2014

Keywords: Extracellular vesicles; pregnancy; microvesicles; exosomes; nanoparticle tracking analysis; pre-eclampsia

\section{INTRODUCTION}

In human pregnancy, the maternal immune system is controlled at every stage of the reproductive process, to promote tolerance to spermatozoa and the semi-allogeneic fetus. Preconception, the maturing oocyte of the pre-ovulatory follicle prepares for its imminent release, and sperm cells must negotiate the hostile female reproductive tract and avoid being phagocytosed by maternal immune cells, to increase the chances of successful fertilization of the oocyte. ${ }^{1}$ Sperm cell capacitation permits fusion with the released oocyte, enabling fertilization to take place. The resulting embryo migrates to the uterus, where it must attach to and invade the endometrium, requiring a proinflammatory environment. ${ }^{2}$ Embryo invasion proceeds as trophoblast signal the presence of the embryo to uterine cells (critically including immune cells which aid the process). From approximately 10 weeks of gestation, when blood flow to the placenta is established, maternal peripheral blood immune cells and immune factors will directly contact the conceptus and therefore, systemic tolerance must be established. This requires a balance between immune tolerance of the fetus and protection against infectious agents for the mother.

Reproductive failure, due to inappropriate maternal immune cell activity, is prevented by mechanisms that target both the innate and acquired immune systems. The gametes and embryo have a relatively small window during which they must evade the maternal immune system. However, the trophoblast cells, made up of the invasive extravillous trophoblast (EVT) and the multinucleated syncytiotrophoblast (STB) must interact with the maternal immune system for practically the entire length of the pregnancy. Semi-allogeneic trophoblast expressing paternal antigens should be recognized as foreign by maternal immune cells and provoke a rejection response. This is prevented by trophoblast cells having a unique expression profile of human leukocyte antigens (HLA); proteins responsible for allorecognition by natural killer (NK) cells and T cells. The STB layer is unique in being HLA null and therefore immunologically inert, while the EVT that invade the decidual layer uniquely downregulate HLA-A and -B expression and only express HLA-C and the non-classical HLA-G, -E and -F Class I MHC antigens. ${ }^{3}$ Immunomodulatory signals are also released during pregnancy as both soluble factors, such as chemokines, cytokines and steroid and protein hormones, and membraneassociated factors in the form of extracellular vesicles (EVs).

EVs are potent modulators of the immune system, with welldefined roles in immune signalling during both physiological and pathological processes. ${ }^{4}$ During the early stages of the human reproductive process, the ovarian follicle, seminal fluid, endometrium, embryo and trophoblast cells are all possible sources of EVs that have the potential to modulate maternal immune function locally. During later pregnancy, the STB of

Nuffield Department of Obstetrics and Gynaecology, University of Oxford John Radcliffe Hospital Oxford, UK

Correspondence: Dr D Tannetta, Nuffield Department of Obstetrics and Gynaecology, University of Oxford John Radcliffe Hospital Oxford, OX3 9DU, UK. E-mail: dionne.tannetta@obs-gyn.ox.ac.uk

Received: 9 May 2014; Accepted: 11 May 2014 
the placenta is the primary source of these EVs; STB releases EVs directly into the maternal blood constituting a major signalling mechanism between fetus and mother. ${ }^{5} \mathrm{EV}$ signalling may be through protein or lipid ligand-receptor interactions or micro-interfering RNAs (miRNAs) which have been found in both soluble and EV associated forms in various bodily fluids (e.g., plasma, urine, saliva and breast milk). ${ }^{6,7}$ These are small RNA species that regulate gene expression post-transcriptionally, as part of a novel mechanism for intercellular exchange of genetic material, which also control immune responses. The placenta expresses 46 unique miRNAs found in the primate specific chromosome 19 microRNA cluster alongside abundant ubiquitous species. ${ }^{8-12}$ These imprinted placental specific miRNAs are the predominant forms of miRNA in the STB layer and trophoblast cells and have been speculated to be immunomodulators in pregnancy. ${ }^{13-16}$

Pregnancy offers a unique opportunity to study EVs in normal physiology. First, unlike any other condition, it is known exactly when the pregnancy begins and when it finishes, allowing EVs to be followed throughout the entire process. Second, many of the reproductive cellular components carry specific markers which allow the EVs to be distinguished from those produced by other cell types and thirdly, the major source of fetal-derived EVs, the placenta, is available at the end of the pregnancy for study.

This review will follow the key stages of the human reproductive process, from pre-conception to established pregnancy, outlining the different sources and subtypes of reproductive EVs, their molecular cargo and summarizing our understanding of their complex interactions with maternal immune cells or their roles in reproduction.

\section{EVs RELEASED BY REPRODUCTIVE CELLS AND TISSUES-FROM NANO- TO MACRO-SIZED MATERIAL}

$\mathrm{EV}$ is a general term encompassing several different vesicle types, released by cells constitutively or in response to specific stimuli or cell stressors, including exosomes, microvesicles, apoptotic vesicles and in pathological situations, necrotic debris. EVs are primarily distinguished on the basis of their size with exosomes, microvesicles and apoptotic vesicles considered to be $30-100 \mathrm{~nm}$, $100 \mathrm{~nm}-1 \mu \mathrm{m}$ and $1-5 \mu \mathrm{m}$, respectively ${ }^{17}$ (Figure 1 ). Not only do these vesicles differ in size, but there are also differences with regard to their formation and protein content. Microvesicles are released from the plasma membrane by direct budding or shedding in response to cellular activation or stress. Exosomes are formed from internalized endocytic vesicles, and are constitutively secreted from the cell. Apoptotic vesicles are released from blebbing cells undergoing apoptosis. STB also releases syncytial nuclear aggregates (approx. 20-500 $\mu \mathrm{m}$ in size), in addition to other EV subtypes $^{18,19}$ (Figure 1).

There are no specific markers to distinguish the subtypes of EVs. Protein components of the 'endosomal-sorting complexes required for transport' (ESCRT complexes) Alix and TSG101, and tetraspanins such as CD63, CD81 and CD9, are enriched in, but not always exclusive to, exosomes. Combined with size, they are used as exosomal markers, while their lower relative abundance in larger vesicles is taken as an indication of microvesicle release. ${ }^{20}$ However, EV populations are often not defined by researchers, hindering elucidation of the EV subtypes released by cells from different reproductive tissues. This is also confounded by the use of different isolation techniques,

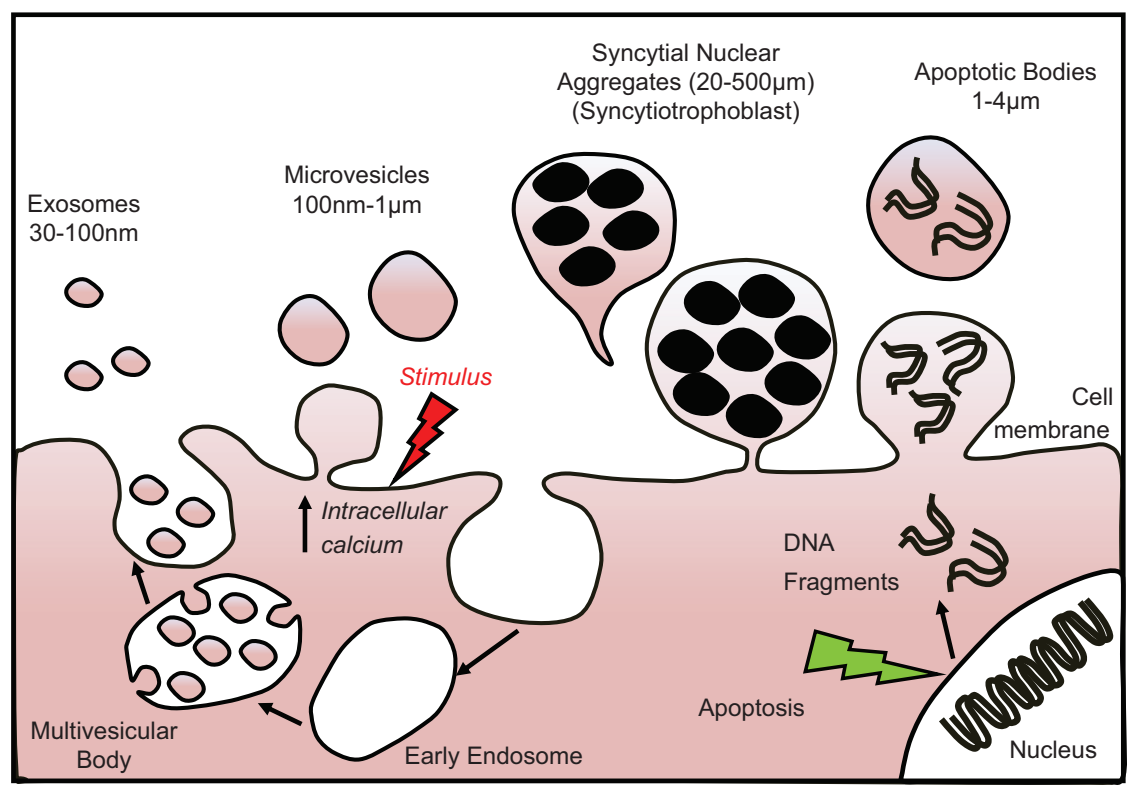

Figure 1 Four subtypes of released material from reproductive tissues. Exosomes $(30-100 \mathrm{~nm})$ are generated from reverse budding of the endosome membrane, resulting in a multivesicular body which fuses with the plasma membrane of the cell and releases exosomes by exocytosis. Microvesicles (100 nm-1 $\mu \mathrm{m})$ are produced by direct budding of the plasma membrane in response to stimuli that trigger an increase in intracellular calcium levels. Apoptotic bodies (1-5 $\mu \mathrm{m})$ are released from cells undergoing apoptosis, while syncytial nuclear aggregates (20$500 \mu \mathrm{m})$ are released from the syncytiotrophoblast on the placental surface. 
resulting in some groups only studying the larger vesicles, ${ }^{21,22}$ while others focus on the smaller exosomes to the exclusion of other vesicle types. ${ }^{23}$ However, future studies separating the different types of reproductive EVs, i.e., exosomes from microvesicles, using techniques such as immunoaffinity beads or differential centrifugation and subsequent functional studies and proteomic and DNA/RNA analysis of their contents will be crucial to determine their relative functional importance.

The four main methodologies used routinely to quantify and phenotype EVs in biological samples, are: (i) enzyme-linked immunosorbent assay; (ii) flow cytometry; (iii) electron microscopy (EM); and (iv) western blotting. More recently, other techniques have been used to investigate and characterize EVs including; cryo-EM, nanoparticle tracking analysis (NTA), dynamic light scattering, resistive pulse sensing (IZON qNano), atomic force microscopy and Raman spectroscopy (as reviewed in Refs. 24-26). Flow cytometry is the most widely used method to investigate EVs, however, as flow cytometers are typically designed to examine cells, analysing small EVs is associated with a number of technical limitations and standardisation issues. One of the major limiting factors is resolving EVs from the instrument electronic noise and this can be variable between instruments. Analogue instruments can resolve EVs down to $\sim 500 \mathrm{~nm}$ in diameter, ${ }^{27,28}$ whereas newer digital flow cytometers are reported to analyse EVs of $\geqslant 300 \mathrm{~nm} .{ }^{29-31}$ Therefore, this limits standard flow cytometric analysis to large microvesicles and apoptotic bodies. The analysis of EVs of $\sim 100 \mathrm{~nm}$ has been demonstrated using a BD Influx flow cytometer, however, this instrument was specifically modified for this purpose. ${ }^{32,33}$ More recently, the Apogee A50 Micro flow cytometer was marketed, featuring an optical design with an improved light scatter detection performance, resulting in enhanced signal/noise ratio and enabling the detection of EVs down to $100 \mathrm{~nm}$ in diameter. ${ }^{34}$

With an appropriate panel of antibodies, multicolour flow cytometry allows the identification of EVs from multiple cellular sources in a single sample, such as those found in blood samples which contain EVs from platelets, red blood cells and leukocytes in non-pregnant individuals, as well as STB-derived EVs in pregnancy ${ }^{29,35}$ However, accurate sizing of EVs cannot be performed by flow cytometry. It is possible to determine the size of EVs by EM, but it is labour intensive, highly subjective and not quantitative. Although this technique is still routinely used, many researchers are now using an alternative method for EV sizing; NTA. NTA determines the size of vesicles from their Brownian motion, by tracking the movement of individual vesicles in real time, and has, for the first time, allowed the accurate sizing and counting of EVs in biological fluids. ${ }^{36}$

\section{EVs AND PRE-PREGNANCY ADAPTATION OF THE MATERNAL REPRODUCTIVE TRACT}

The immune system of the female reproductive tract is finely tuned to cope with reproductive processes. It must provide a robust defence against pathogenic agents whilst tolerating the presence of semen harbouring immunogenic paternal alloantigens, and subsequently provide a nurturing environment for the semiallogeneic conceptus. In this section, we will review the literature pertaining to EVs present in follicular fluids of ovulatory follicles, secreted from the endometrium, present in seminal fluid or released from the developing embryo prior to implantation, focusing on any known immune interactions.

\section{Oocyte EVs}

Sperm and oocyte fusion is essential for fertilisation. The tetraspanin CD9 is known to play an important role in gamete fusion in mice, as CD9-deficient oocytes are unable to fuse with sperm. ${ }^{37,38}$ A possible role for CD9 in the transfer of oocyte material to sperm has been investigated; however, this topic remains controversial. ${ }^{39-41}$ Using a transgenic mouse model, oocytes were shown to transfer CD9 to the sperm head via vesicles described as 'exosome-like'. ${ }^{41}$ These CD9-associated EVs were localized to the perivitelline space (PVS) of the oocyte and were shown to be between 50 and $250 \mathrm{~nm}$ in diameter and express two known exosome components-ganglioside GM3 and heat shock protein 90 . Another study also confirmed the presence of EVs of exosome size $(50-150 \mathrm{~nm})$ in the oocyte PVS, some of which were associated with CD9. ${ }^{39}$ There are conflicting reports as to whether the accumulation of EVs in the PVS is altered in CD9 null oocytes and whether EV production and secretion from the oocyte is CD9 dependent. ${ }^{39,41}$ Sperm cultured in medium containing EVs from fluorescently labelled CD9 null oocytes capture these EVs and in turn the sperm acquires fluorescence, thereby suggesting that oocyte EVs are transported to sperm, but this process is independent of CD9. ${ }^{39}$ One study showed sperm fusion with wildtype oocytes or CD9 null oocytes cultured in conditioned medium containing CD9-associated EVs isolated from wild-type oocytes. ${ }^{41}$ These data suggest that CD9-associated EVs are released from the oocyte prior to fertilisation and are required for sperm fusion. Contrary to this report, two independent studies have failed to replicate the ability of CD9 null oocytes to fuse with sperm after co-incubation with wild-type oocytes or medium containing CD9-associated EVs. ${ }^{39,40}$

The tetraspanin CD81 is expressed on the surface of the mouse oocyte ${ }^{42}$ and surrounding somatic cells ${ }^{43}$ and may also play a role in sperm-oocyte membrane fusion. ${ }^{42-44}$ Subcellular expression of CD9 and CD81 in the mouse oocyte demonstrates that these are predominantly localized in the PVS and zona pellucida respectively. It has been proposed that CD9 is primarily produced by the oocyte, whereas CD81 is primarily produced in the surrounding cumulus cells. ${ }^{44} \mathrm{~A}$ model has been proposed where, the localisation of CD9 and CD81 to their respective oocyte compartments is essential for sperm fusion, and as sperm penetrate the PVS both CD9 and CD81 are secreted via exosomes and attach to sperm. ${ }^{44}$

Given the size of the oocyte and surrounding somatic cells, and the potential therefore to only produce a limited number of EVs, it would not be surprising to find that oocyte/somatic cellderived EVs only play a role in close proximity within the ovarian follicle, rather than a broader role modulating the uterine lumen environment. Their limited numbers may also 
help to explain the need to contain EVs within the oocyte PVS and zona pellucida.

\section{Follicular fluid EVs}

Follicular fluid contains a plethora of biochemical and metabolic substances that regulate oocyte maturation and follicle growth ${ }^{45}$ and recently it was reported that follicular fluid also contains EVs. ${ }^{4-49}$ Ovarian follicular fluid EVs were first described in the horse. ${ }^{46}$ This study identified miRNAs within follicular fluid EVs, identical to those in the somatic cells (granulosa and cumulus). These EVs bind and are taken up by granulosa cells both in vitro and in vivo and therefore may constitute a new form of ovarian cell-cell communication. Significant variation in levels of follicular fluid miRNA-associated EVs in old versus young mares also suggest that these may be indicative of age-related decline in oocyte quality. ${ }^{46}$ Similarly bovine follicular fluid contains exosome-associated miRNAs. ${ }^{49}$ Bovine granulosa cells take-up follicular fluid exosome-associated miRNAs via endocytosis in vitro, significantly increasing the level of endogenous miRNAs and changing mRNA expression of target genes in granulosa cells known to be involved in follicle development. These follicular fluid exosome-associated miRNAs may also play a role in regulating oocyte growth as they are differentially expressed in follicles containing growing versus fully grown oocytes. ${ }^{49}$ Using differential centrifugation and NTA, our laboratory has shown the presence of exosome and microvesicle sized EVs in human follicular fluid (Figure 2). Human follicular fluid EVs are polydisperse and include both microvesicle and exosome sized EVs, with a mean diameter of $\sim 220 \mathrm{~nm}$ (Figure 2ai). Two other studies have also confirmed the presence of human follicular fluid derived EVs. ${ }^{47,48}$ Human follicular fluid EVs contain numerous miRNAs, some of which target genes that are important in regulating pathways of reproduction, metabolism and endocrine function. ${ }^{48}$ However, as yet, possible interactions of follicular fluid EVs and maternal immune cells have not been investigated.

\section{Endometrial EVs}

Fertilisation of the oocyte occurs in the oviduct, and a novel role for exosomes residing in the oviduct of mice has been proposed, termed 'oviductosomes'. Oviductosomes express a $\mathrm{Ca}^{2+}$ regulatory protein, PMCA4a which is transferred to sperm. PMCA4a has roles in sperm storage in the oviduct, capacitation and the acrosome reaction, therefore it is proposed these oviductosomes may have an important role in fertility. ${ }^{50}$

EVs, predominantly $50-150 \mathrm{~nm}$ in diameter, have been identified in human uterine fluid and dissociated mucus. ${ }^{51}$ Most of the EVs found in the uterine cavity are likely to be of exosome origin, derived from the endometrial epithelium, as the two tetraspanins CD9 and CD63 are present on the apical surfaces of endometrial epithelial cells. ${ }^{51}$ It is hypothesized that the endometrial epithelial cells or the blastocyst acquire endometrial exosomes to improve implantation. ${ }^{51}$

Endometrial remodelling by matrix metalloproteinases is essential during each menstrual cycle in preparation for embryo implantation. Using human endometrial epithelial cell lines, a possible role has emerged for endometrial epithelial EVs in regulating this process. ${ }^{51-53}$ Microvesicles from a human uterine epithelial cell line were shown to contain the extracellular matrix metalloprotease inducer (EMMPRIN (CD147)) which stimulated uterine stromal fibroblast matrix metalloproteinase production. ${ }^{52}$ Microvesicle EMMPRIN secretion is stimulated by the ovarian hormones estradiol and progesterone and also by the pro-inflammatory cytokine IL- $1 \beta$, thereby suggesting that its secretion is regulated as part of an inflammatory response. ${ }^{52}$ It is proposed that EMMPRIN is secreted as a soluble protein in response to degradation of microvesicles. ${ }^{52}$ EMMPRIN has also been shown to be released in microvesicles in response to $G$ protein-coupled receptor 30 stimulation. ${ }^{53}$

The analysis of miRNAs from the human uterine epithelial cell line ECC1 demonstrated sorting of certain miRNAs into EVs, showing $>200$ miRNAs were co-expressed by the ECC1 parent cells and the ECC1 EVs, 13 specific to EVs and 5 specific to the parent cells. ${ }^{51}$ Predicted target genes of the EV miRNAs included those known to play a role in regulating embryo implantation such as extracellular matrix receptor interactions, adherens and tight junctional proteins and the Jak-STAT signalling and VEGF signalling pathways. ${ }^{51}$

\section{Seminal fluid EVs}

Seminal fluid contains large numbers of EVs, the majority of which in humans originate from the epithelial cells lining the acinar ducts of the prostate gland and are called prostasomes, although other epithelial cells of the male reproductive tract also secrete EVs, such as from the epididymis (epididymosomes) and vesicular glands, reviewed elsewhere. ${ }^{1,54}$ Extensive analysis of prostasomes has been performed, summarized by Ronquist. ${ }^{54}$ We have also used NTA to determine the size of prostasomes. As previously reported,$^{54}$ prostasomes are very small in size, with a modal peak at $\sim 120 \mathrm{~nm}$ (Figure 2aii). Prostasomes play an important role in fertility; they bind to sperm and are thought to enhance their motility and ability for capacitation - they are enriched in divalent cations known to be involved with sperm motility, such as $\mathrm{Ca}^{2+}$, and contain enzymes which control their levels. They also transfer hydrolases such as ecto-diadenosine polyphosphate hydrolase and are rich in sphingomyelin with a high cholesterol/phospholipid ratio, all of which regulate the acrosome reaction. They also contain fragments of genomic DNA, although it is not clear if this has a functional consequence. Chromogranin B confers bactericidal properties to prostasomes and importantly they also prevent immune cell recognition of sperm in the female reproductive tract and have immune modulatory properties. Prostasomes inhibit lymphocyte proliferation and macrophage/neutrophil functions. ${ }^{55}$ Direct inhibition of NK cells by prostasomal expression of $\mathrm{CD} 48$, the ligand for the $\mathrm{CD} 244$ (NK activating receptor 2B4), has been identified. ${ }^{56}$ They also contain the complement regulatory proteins CD59 (a GPI-anchored membrane attack complex inhibitory protein) and CD46 (a cofactor for proteolytic inactivation of $\mathrm{C} 3 \mathrm{~b}$ and $\mathrm{C} 4 \mathrm{~b}$ ) - both of which protect sperm from lysis mediated by the female complement system. ${ }^{57,58}$ 
Ai

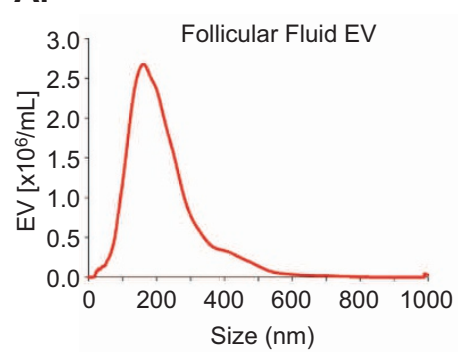

Aii

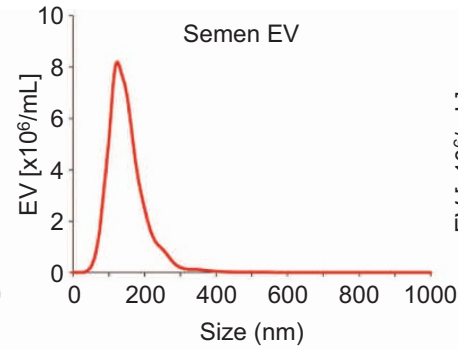

Size $(\mathrm{nm})$
$\mathrm{Bi}$

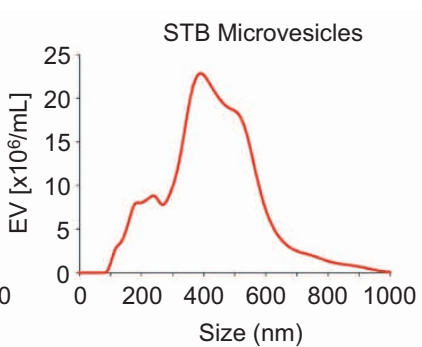

$\mathbf{C i}$

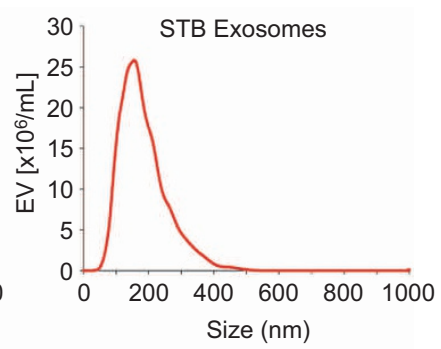

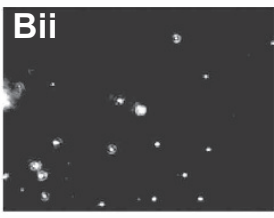
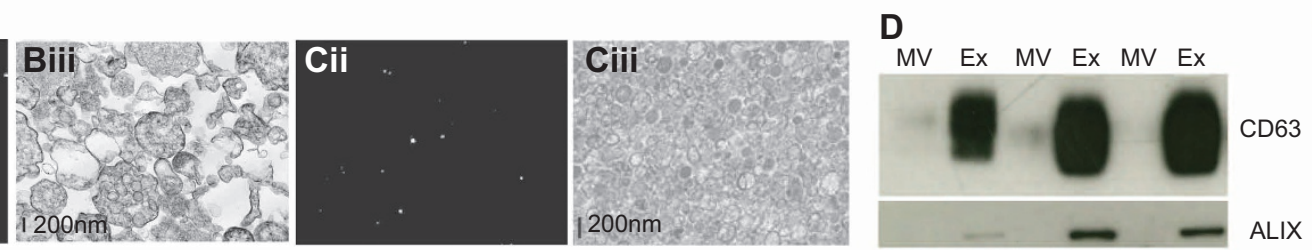

Figure 2 Representative NTA profiles of EVs isolated from (ai) follicular fluid, (aii) seminal fluid and (bi) microvesicle-enriched and (ci) exosomeenriched fractions prepared from perfused placenta-derived STB EV, fractionated using differential centrifugation, with accompanying (bii, cii) NTA video screen shots and (biii, ciii) electron microscopy images. (d) Western blotting of STB MVs and STB Exs showing enrichment of exosomal markers CD63 and Alix in the STB exosome fraction. Ex, exosome; MV, microvesicle; NTA, nanoparticle tracking analysis; STB, syncytiotrophoblast.

High levels of reactive oxygen species in semen samples are associated with infertility. It is possible that contaminating neutrophils are a source of reactive oxygen species generation, and prostasomes are thought to reduce reactive oxygen species production..$^{59}$ Finally, Galectin-3 (a multifaceted, immunomodulatory lectin) is expressed on prostasomes and probably has wide ranging functions within the female reproductive tract. ${ }^{60}$

\section{Pre-implantation embryo EVs}

EVs from the pre-implantation embryo have not yet been reported, but it is likely that the embryo has the capacity to release them. Although embryo culture supernatants can be obtained from in vitro fertilization (IVF) clinics, we have found that the in vitro fertilization (IVF) culture media alone contains high levels of EVs, probably from the nutrients supplemented for embryo growth, making detection of specific embryoderived EVs challenging.

\section{EVs AND ADAPTATION OF THE MATERNAL SYSTEM DURING PREGNANCY}

Following implantation and throughout the remainder of pregnancy, trophoblast cells form the interface between the maternal immune cells and the fetus. Differentiation of the trophectoderm cell lineage gives rise to two forms of trophoblast cells, villous cytotrophoblast (CTB) and EVT. EVT proliferate in the tips of the anchoring villi attached to the uterine wall, then acquire invasive characteristics and migrate into the decidua and, as pregnancy progresses, into the myometrium. Both interstitial and endovascular subtypes of EVT form part of a coordinated response with maternal uterine NK and macrophage cells to adapt blood flow to the needs of the placenta and fetus, by destroying the muscular walls and replacing the endothelial lining of the distal portions of the uterine spiral arteries with EVT. ${ }^{61-63}$ The CTB fuse into multinucleated STB covering the villi of the placenta that are bathed in nutrient rich secretions from endometrial glands until towards the end of the first trimester, when maternal blood flow to the placenta is established. ${ }^{64}$ This then brings into play the largest maternal/ fetal interface-the STB of the human haemochorial placenta in direct contact with the maternal blood. STB becomes the dominant site of conceptus EV release and the release of STB EVs into the maternal circulation extends this interface beyond the uterus and out into the maternal systemic vasculature. ${ }^{65}$

Taking into account the type of trophoblast EVs and the source of the immune cells used to study their interaction, maternal immune cell modulation and the role played by trophoblast EVs during pregnancy will be discussed (literature for interactions with adaptive and innate immune cells are summarized in Tables 1 and 2, respectively).

\section{EVT EVs}

Release of EVs by EVT during early pregnancy, has been demonstrated both in vivo and in vitro through detection of HLA-G positive EVs. HLA-G is expressed on EVT but not STB. Cultured first trimester explants and the EVT like cell line Swan71 release HLA-G-positive EVs, and HLA-G-positive EVs have been detected in the maternal circulation. ${ }^{66-68}$ Using flow cytometry, circulating HLA-G-positive EVs were identified throughout pregnancy, with amounts decreasing towards term. ${ }^{67}$ Detection of HLA-G-positive EVs was also reported in the third trimester of pregnancy; ${ }^{68}$ however both accounts of detectable levels of circulating HLA-G positive vesicles are surprising given the very small surface area of endovascular EVT exposed to the large maternal blood volume. ${ }^{69}$ To date, only one study has characterized the morphology of EVs released by EVT using Swan71 cell line and a protocol designed 


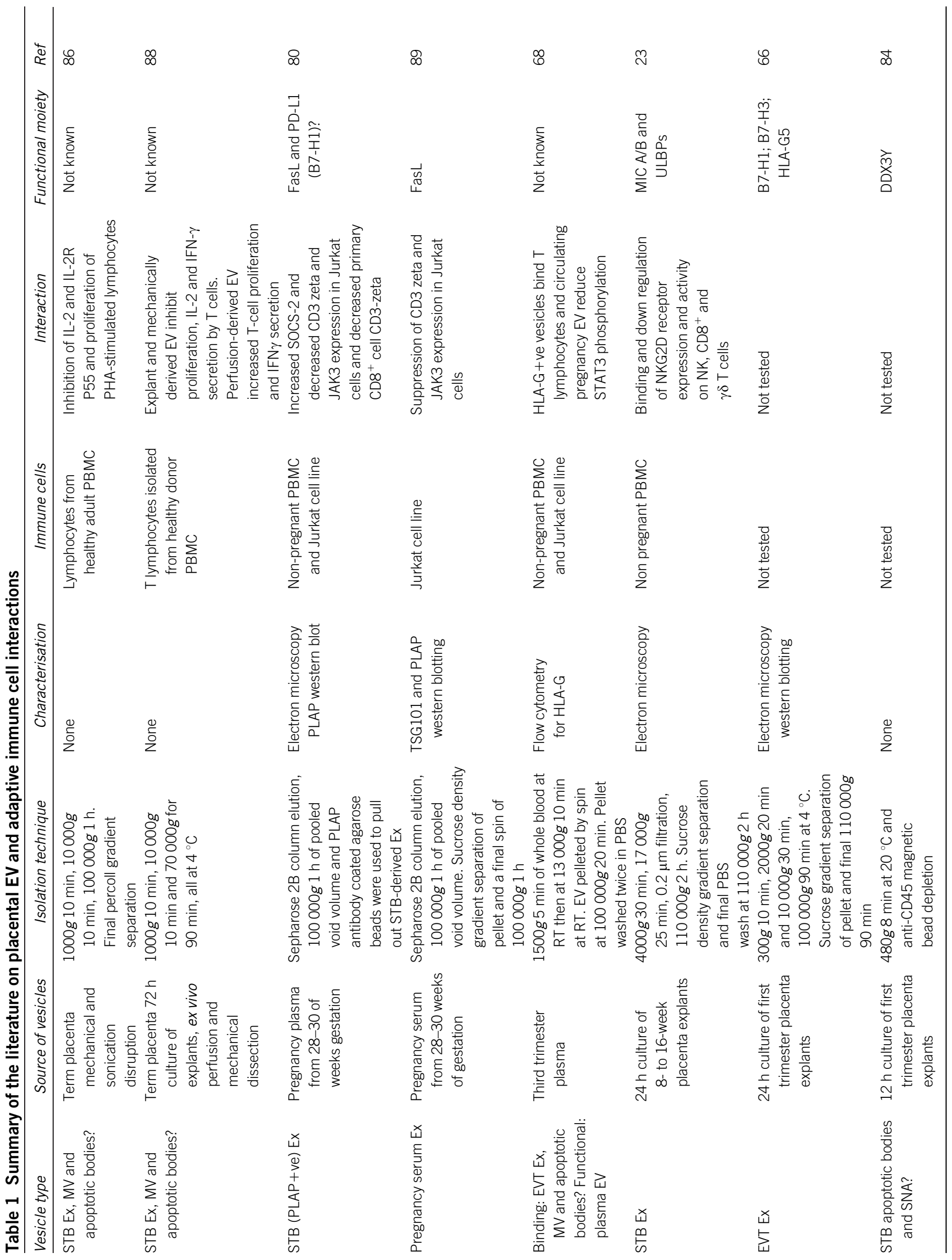


to enrich for exosomes. ${ }^{70}$ Density (sucrose gradient), morphology (EM) and size (dynamic light scattering) analysis strongly suggested that Swan71 cells release exosomes. This finding, together with reports that HLA-G-positive vesicles can be detected by flow cytometry, suggests that native EVT release both exosomes and microvesicles.

Evidence for immunomodulatory effects of EVT-derived EVs is also limited (Tables 1 and 2). Circulating HLA-G-positive EVs present in plasma from healthy term pregnant women have been reported to bind at low levels to T lymphocytes ex vivo. ${ }^{68}$ The same study showed that EVs isolated from healthy term pregnancy plasma modestly decreased peripheral $\mathrm{T}$ lymphocyte and Jurkat cell STAT3 phosphorylation. ${ }^{68}$ Potential to affect immune cell function is also suggested by the observation that HLA-G-positive exosomes from first trimester explants carry immunomodulatory proteins $\mathrm{B} 7-\mathrm{H} 1$ and $\mathrm{B} 7-\mathrm{H} 3$, which have previously been shown to modulate effector $\mathrm{T}$ cell function. B7$\mathrm{H} 1$, also known as PD-L1, is implicated in promoting maternal/ fetal tolerance. ${ }^{66}$ HLA-G itself also has immunosuppressive properties thought to protect the fetus from immune rejection; HLA-G binds with high affinity to the NK inhibitory receptor LILRB1 inhibiting NK cell killing activity. ${ }^{71,72}$ Vesicles, thought to be exosomes, isolated from the EVT-like cell line Swan71, have been shown to stimulate a pro-inflammatory cytokine and chemokine profile in both the THP-1 monocytic cell line and cultures of primary macrophages, ${ }^{73,74}$ suggesting monocytic pro-inflammatory as well as lymphocytic immunosuppressive activity of EVT exosomes.

It is not known whether the early STB layer releases any vesicular material at the time when the developing intervillous space is filled with endometrial gland secretions, and whether these EVs would interact with maternal immune cells. Interstitial trafficking of STB derived EVs through the decidua cannot be ruled out, especially during the very early stages of pregnancy when the STB forms within the decidual layer, but this has not yet been investigated. However, STB EVs from the late first trimester onwards, around the time when placental blood flow is established, are by far the most studied EVs derived from reproductive tissue. This is due to the availability of human placental tissue from first trimester terminations and at term. ${ }^{69,75}$ Term placentas are particularly useful as they can yield large quantities of STB EVs derived from a fresh, primary tissue, especially if the placenta is obtained from an elective caesarean section and has therefore not been subjected to the stresses of labour. It is important to remember however that placentas from normal pregnancies are not normally available prior to term; therefore, identification of STB in the maternal blood will be the only way we can study placenta EVs throughout later gestations.

We have used NTA to determine the size of STB EVs prepared by perfusion of term placentas (Figure 2). Sizes of STB EVs isolated from placental perfusate range from approximately $40 \mathrm{~nm}$ upwards, with the majority $(>90 \%)$ being less than $1 \mu \mathrm{m}$ and $70 \%$ being less than $300 \mathrm{~nm}$ in diameter, suggesting that these EVs are also predominantly a mixture of 


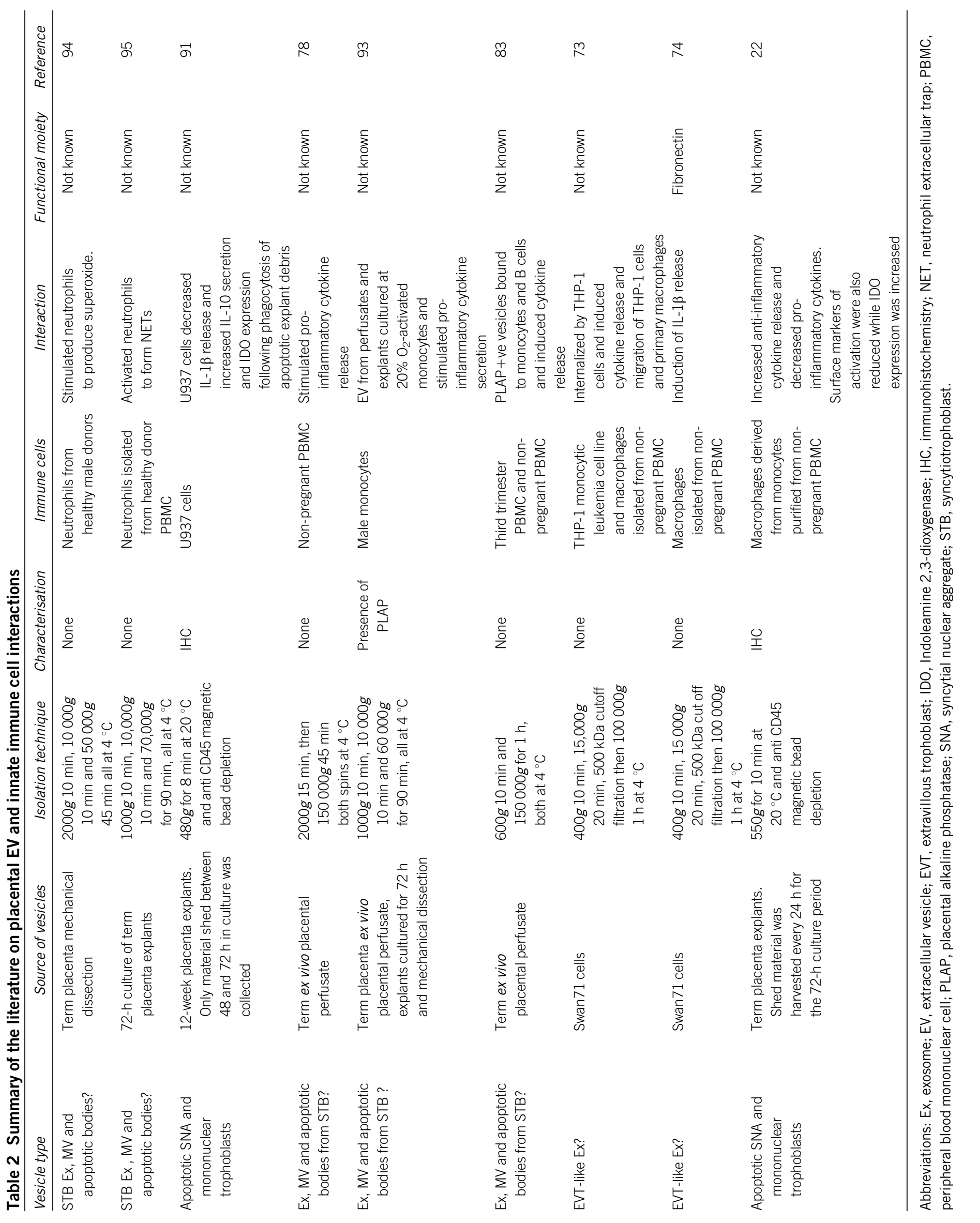


exosomes and microvesicles. ${ }^{18,31}$ Using differential centrifugation, placental perfusion-derived STB EVs can also be fractionated to give enriched STB microvesicle and STB exosome preparations, characterized using NTA (Figure 2bi and bii; STB microvesicles and Figure 2ci and 2cii; STB exosomes), transmission EM (Figure 2biii; STB microvesicles and Figure 2ciii; STB exosomes) and western blotting for exosome markers CD63 and Alix (Figure 2d) (Tannetta and Dragovic, unpublished data).

\section{Identification of syncytiotrophoblast EVs in the maternal circulation}

The deportation of STB material into the maternal circulation has been recognized for many years. ${ }^{76}$ Increased levels of STB EVs were found in the uterine vein blood compared to the peripheral blood, consistent with their placental origin. ${ }^{77}$ Levels measured by STB EV enzyme-linked immunosorbent assay, which captures STB EV using an antibody to placental alkaline phosphatase (PLAP), a STB marker, showed increases with advancing pregnancy ${ }^{78}$ and labour ${ }^{79}$ returning to nonpregnant levels in most cases by $48 \mathrm{~h}$ post-delivery. Flow cytometry has also been used to confirm the particulate nature of the STB material pelleted from maternal plasma using two STB-specific monoclonal antibodies, one that binds PLAP and another called ED822 which recognizes an as yet unknown antigen on the apical surface of the STB. ${ }^{29,35,67,77,78}$ PLAP-positive EVs are found circulating throughout pregnancy, with levels increasing towards term. ${ }^{78}$ PLAP-positive EVs have also been isolated directly from pregnancy plasma, taken between 26 and 28 weeks gestation, using agarose beads coated with a PLAP-specific antibody. ${ }^{80}$

The composition of EVs in terms of the proportions of exosomes, microvesicles, apoptotic bodies and syncytial nuclear aggregates will have an important bearing on their functional characteristics and distribution throughout the body. As such, circulating STB EVs give only a glimpse of the material released from the placental surface. Syncytial nuclear aggregates have been identified in uterine vein and inferior vena cava blood. However, due to their size, syncytial nuclear aggregates are mostly trapped in the pulmonary capillary bed, ${ }^{81}$ while smaller STB EVs are able to pass through the lung capillaries and enter the peripheral circulation. ${ }^{77}$ Further loss of STB EVs, filtered out by organs such as the liver and spleen, is also possible, although this has not been investigated. ${ }^{82}$ Meanwhile, phagocytic immune and endothelial cells constantly clear cellular debris from the circulation that could include STB derived material. ${ }^{78}$ This raises questions such as: do STB EVs have target cells with which they interact?, what biological effects do the STB EVs have on the cells and organs they come into contact with? and what is the significance of the material not removed from the circulation?

\section{Functional effects of syncytiotrophoblast EVs throughout pregnancy}

STB EVs have the potential to modulate maternal immune cell function at a local and systemic level (Tables 1 and 2). STB EVs are bound at detectable levels to monocytes from the second trimester and increase further at term in vivo. ${ }^{78}$ Studies carried out in vitro also showed that monocytes and B cells rapidly bound and internalized STB EVs, suggesting possible functional interactions. ${ }^{83}$ Intriguingly, NK cell and T-cell binding of STB EVs has not been reported, even though several studies, outlined below, have shown STB EVs to have immunosuppressive effects on the function of these cell types.

Prevention of fetal rejection, in part by the suppression of maternal cell mediated immune responses, has long been recognized. Evidence continues to grow that placental EVs form part of a range of immunosuppressive factors released by the placenta that are involved in this process. The Y chromosome-linked minor histocompatibility antigen DDX3Y has been shown to be released from first trimester placental explant bound to STB debris and the authors speculate that this may lead to the induction of antigen specific regulatory $\mathrm{CD}^{+} \mathrm{T}$ cells, conferring immunological tolerance to the fetus. ${ }^{84}$ Midfirst to early-second trimester explants also release STB exosomes with biologically active MHC class I chain-related (MIC $\mathrm{A} / \mathrm{B}$ ) proteins and UL-16 binding proteins on their surface, able to initiate internalization of $\mathrm{NK}$ cell activating receptor NKG2D on NK cells, cytotoxic T lymphocytes and $\gamma \delta$ T cells, reducing cell surface NKG2D expression and subsequent cytotoxic capacity. ${ }^{23,85} \mathrm{~T}$ cell responses have also been shown to be significantly inhibited by several different preparations of placental EVs, measured by PHA and mixed lymphocyte response induced proliferation, ${ }^{86-88}$ Fas ligand and TRAIL-mediated lymphocyte and activated peripheral blood mononuclear cell (PBMC) apoptosis and CD3-zeta loss. ${ }^{80,87,89,90}$ Immunosuppressive activity has also been demonstrated with much larger shed STB material. Phagocytosis of large apoptotic mononuclear trophoblast and syncytial nuclear aggregates from cultured first trimester placental explants stimulated IL10 release and indoleamine 2,3-dioxygenase (IDO) expression, and decreased IL-1 $\beta$ secretion in monocytic U937 cells. ${ }^{91}$ In addition, large trophoblast debris from term placenta explants decreased surface expression of MHC class II molecules and inflammatory cytokine release, with a concomitant increase in anti-inflammatory cytokines and IDO expression, from primary macrophages. ${ }^{22}$ Therefore, larger apoptotic trophoblast debris may have an integral role in tolerizing maternal immune cells to fetal alloantigens. ${ }^{21}$

While the immunosuppressive effects of placental EVs on maternal immune cells suggest a role for STB EVs in the mechanism by which the placenta avoids immune rejection, the situation is more complicated than this because maternal innate immune responses are also activated in normal pregnancy and bring about a systemic inflammatory state. ${ }^{92}$ This may seem counterintuitive; however, controlled inflammation, in the face of suppressed T and NK cell-mediated immune responses, may be beneficial in helping the mother fight infection. There is growing evidence that placental EVs play a role in the maternal systemic inflammatory response. We and others have shown that preparations of STB EVs stimulate PBMC and 
monocytes to release a range of proinflammatory cytokines (including TNF $\alpha$, MIP- $1 \alpha$, IL- $1 \alpha$, IL-1 $\beta$, IL-6, IL-8, IL-12, IL-18 and IFN- $\gamma)^{73,74,78,83,93}$ Reports of the effects of STB EVs on granulocyte function are limited, but term placental EV preparations have been shown to directly stimulate neutrophils, resulting in increased superoxide production and the formation of neutrophil extracellular lattices. ${ }^{94,95}$

As discussed above, STB EVs have a wide range of functional activities suggesting that they carry a variety of bioactive molecules. Several EV-associated biologically active factors have already been identified, a summary of which is shown in Figure 3. A crucial step now is to further define which molecules are present on the different vesicle types and which are responsible for the functional effects. We have performed proteomic analysis on perfused placental EVs using multidimensional protein identification technology. ${ }^{96}$ Over 2000 proteins were identified and included potential immunomodulatory molecules such as alarmins (HSP70, high mobility group box 1 , fetal haemoglobin and galectin 3), immunoregulatory molecules (CD200, CD147 and galectin 1) and complement regulatory molecules (CD55 and CD59) (Tannetta et al., unpublished observations). Very few studies have specifically investigated placental vesicle-associated miRNA.

Several placenta-specific miRNAs are released in exosomes by the trophoblast cell line BeWo and isolated human term trophoblast. ${ }^{13,14}$ Using Affymetrix GeneChipR miRNA arrays we also identified five placental specific miRNAs in term placental perfusion-derived EVs: 517a, 512-3p, 517b, 518b and 519a (Tannetta et al., unpublished observations), which have previously been reported in the placenta and maternal circulation. ${ }^{10,13}$ Using qRTPCR, Cronqvist et al..$^{20}$ also demonstrated placental miRNA in placental perfusion-derived EVs. Moreover, isolated trophoblast from term placenta, which fuse in culture to form STB, release exosomes able to transfer viral resistance to recipient cells by inducing autophagy through the delivery of chromosome 19 microRNA cluster miRNAs, ${ }^{97}$ demonstrating yet another mechanism of STB EVs modulation of maternal immune responses.

\section{AMNIOTIC FLUID EVs}

The amniotic fluid is unsurprisingly rich in EVs, as fetal waste products are secreted into this medium and fetal urine contains high levels of EVs. Recently a role has emerged for amniotic fluid EVs in controlling inflammation in the fetal compartment. Exosomes are detected in second trimester amniotic fluids and contain the inducible heat shock protein 72 , which is a known inhibitor of immune activity. ${ }^{98,99}$ Amniotic fluid exosomes are also phagocytosed by the human monocytic precursor cell line THP-1, inducing cytokine production such as IL-1 $\beta$, TNF- $\alpha$ and IL- 6 leading to STAT-3 activation and an immunosuppressive phenotype. ${ }^{100}$ However, maternal immune cells do not contact amniotic fluid and therefore this result may be a reflection of the immune-inhibitory nature of exosomes rather than an amniotic fluid EV-specific phenotype.

\section{CLINICAL PERSPECTIVES}

EVs have been extensively studied in a wide variety of disease pathologies, including autoimmune disorders, inflammatory diseases and cancer. EVs are also implicated in pathological processes of pregnancy, particularly preeclampsia (PE); however, a role for EVs in other reproductive disorders such as preterm labour is also emerging. In developed countries about $5 \%-7 \%$ of births are pre-term. Interestingly, plasma levels of exosomes at 28-30 weeks are reduced in women who deliver preterm compared to women who deliver at term, and these exosomes contain less of the immune inhibitory molecule FasL, suggesting impaired suppression of cytotoxic T-cell activity. ${ }^{89}$ Anti-sperm antibodies, which can occur in human semen or the serum of both men and women, have been linked with male infertility, although the clinical association remains controversial. ${ }^{101}$ Anti-sperm antibodies also bind to prostasomes, ${ }^{102}$ so could alter their function. Several antigens have been identified on prostasomes, such as the prolactin-inducible protein, which has various immunological functions. ${ }^{103}$ Although implicated in modulation of the immune response, as yet there are no known clinical associations between prostasomes and fertility. Research is focused towards using prostasomes as a biomarker for prostate cancer, as prostate-specific antigen is known to be detected on prostasomes, and a small study has shown that prostate cancer patients have prostasomes in their blood plasma. ${ }^{104}$ In addition, the complement evading protein found on prostasomes CD59, is elevated in cancer cells which may aid tumour immune evasion. ${ }^{54} \mathrm{~A}$ recent study examining human follicular fluid and its supernatant in healthy controls and polycystic ovarian syndrome patients identified miRNAs in EVs and the supernatant. ${ }^{48}$ Two miRNAs present in follicular fluid EV and the supernatant; miR-132 and miR-320, which regulate estradiol concentrations, were significantly decreased in polycystic ovarian syndrome patients compared to healthy controls. ${ }^{48}$ Undoubtedly, further research into functional effects of EVs associated with reproduction will yield other clinical observations.

Most research on reproductive cell EVs has focused on PE. $\mathrm{PE}$ is a disorder of human pregnancy which affects $2.5 \%-3.0 \%$ of women, with potential to be lethal or detrimental to longterm health for both the mother and baby. ${ }^{96,105} \mathrm{PE}$ develops in two stages; the first (preclinical) stage comprises poor spiral artery remodelling (8-18 weeks), leading to dysfunctional perfusion and placental oxidative stress. ${ }^{106}$ This stimulates the release of placental factors into maternal blood that cause the second, clinical stage (after 20 weeks) characterized by the maternal syndrome of systemic vascular inflammation, that underlies the symptoms of hypertension, proteinuria, oedema, activation of the coagulation system and in severe cases, eclampsia, typified by convulsions. ${ }^{107}$

Several studies, using enzyme-linked immunosorbent assay methods, have shown increased levels of placental EVs in the maternal circulation in PE, with levels correlated to disease severity. ${ }^{77,108,109}$ Increased EV shedding also appears to be key to the development of the maternal syndrome of PE as 
increased levels were specific to PE complicated by fetal growth restriction and were not evident in normotensive fetal growth restriction, despite similar placental pathology ${ }^{108} \mathrm{~A}$ significant increase in placental EV shedding in PE women during labour, may also play a part in postpartum worsening of the disease. ${ }^{79}$ Results of flow cytometry studies have been less consistent with some studies showing increased plasma levels of placental EVs in PE, while others found no difference between PE and normal pregnancy. ${ }^{29,35,67,78,110}$

Qualitative as well as quantitative differences in placental EVs shed in PE, such as changes in the types of EVs released and the molecular cargo carried by the EVs, could alter their biological function. There are limited studies addressing this issue due to availability of tissue from well-defined PE pregnancies. NTA analysis of PE and normal placental perfusionderived EVs showed a significant increase in vesicle size in PE, suggesting a shift in the balance towards shedding of more STB microvesicles which could alter their overall functional effects to a more pro-inflammatory, anti- angiogenic and procoagulant state. ${ }^{31,111}$ Treatment of PBMC with EVs from PE placenta explants caused significantly higher production of several proinflammatory cytokines and chemokines, including IL-1 $\beta$, compared to normal placental EVs. ${ }^{112}$ Increased placental EV stimulated neutrophil activation is also suggested by higher levels of superoxide production induced by PE placenta EVs and increased formation of neutrophil extracellular lattices in the intervillous space of PE placentae. ${ }^{88,94}$ Possible functional mediators include peroxidized lipids due to increased placental oxidation in PE. ${ }^{113}$ Excessive activation of the coagulation system and increased platelet activation are also features of PE. ${ }^{114}$ PE placental-perfusion EVs have higher functional tissue factor levels than those from normal placentas, implicating them in the excessive activation of the clotting system seen in this disorder. ${ }^{115,116}$ Placental EVs have also been shown to affect the function of endothelial cells, inhibiting their proliferation and growth as a monolayer in vitro ${ }^{117-119}$ and inhibiting the relaxation of preconstricted blood vessels ex vivo. ${ }^{17,119,120}$ Furthermore, when human umbilical vein endothelial cells are cultured with placental EVs the culture supernatants can secondarily activate neutrophils, demonstrating the potential for a vicious cycle of inflammatory activation. ${ }^{21}$ To date, no differential effects of PE and control placental EVs on endothelial cells has been shown; however, the disruptive effects of placental EVs on endothelial cell function demonstrated in vitro and ex vivo and discussed above suggest a contribution of placental EVs to the endothelial dysfunction characteristic to the maternal syndrome of PE. ${ }^{117}$

\section{DISCUSSION}

The field of EV research has grown exponentially in the last 10 years and continues to grow with new findings confirming the involvement of EVs in normal physiology and disease. This is also true for EVs from reproductive tissues and the role they play in the successful establishment of pregnancy. However, by taking an overview of the literature regarding reproductive EVs, it becomes apparent that further work is needed to better understand the source and role of EVs in human reproduction. As outlined in this review, EVs have been identified in a variety of reproductive fluids or are known to be produced by certain human reproductive cells and to carry a multitude of functional moieties (Figure 3). However, it is not known if the sperm themselves produce EVs. Similarly, it is not yet known if human female gametes secrete EVs, although evidence from murine studies suggests that oocytes do produce EVs which bind to sperm and aid fertilisation. It is also not known if the pre-implantation embryo secretes EVs, although, as both the oocyte (in mouse) and trophoblast cells secrete EVs, it is likely that the pre-implantation embryo also has this capacity.

Research into the targeting of reproductive tissue EVs to the maternal immune system also has far to go. The different reproductive EVs will encounter highly specialized maternal immune cell niches, such as the immune cells of the uterine epithelial mucosa (oocyte, follicular fluid, semen and preimplantation embryo EVs), decidua (early STB and interstitial EVT EVs) and peripheral circulation (endovascular EVT and STB EVs). Each niche has its own specialized immune cell population and cytokine and chemokine microenvironment suggesting niche-specific effects of EVs. Proteomic and miRNA screening of EVs has identified many candidate molecules carried by various EV types; as we have described here, however, functional studies are still required to confirm their association. Also the downstream consequences of immune cell modulation in each niche will be very different, with more local effects in the uterine lumen and decidua, whereas effects of STB EVs in the maternal circulation could have implications for multiple organs and vascular cell types. This presents challenges in designing models to better understand the role of reproductive EVs in establishing successful pregnancy. These include modelling of the specialized immune cells found in each niche, such as uterine NK cells of the decidua and immune cells resident in organs (such as Kupffer cells in the liver). However, studies to date have focused on using peripheral blood immune cells, which are easier to obtain, but have different functions. Length of exposure to each reproductive EV population may also need to be taken into account. Multiple exposures to semen EVs can occur before a pregnancy is established, unlike STB EVs where each exposure is unique but slow and sustained, gradually increasing from approximately 10 weeks of gestation, with the onset of placental perfusion with maternal blood, to reach a maximum at term. However, each niche may be important in driving maternal immune cell activation and tolerance at specific stages of pregnancy. Further research is therefore required to fully understand the role each EV type and subtype plays in the promotion of a successful pregnancy.

STB-derived EVs are the most abundant and most studied type of reproductive EVs. Results to date suggest that STB EVs released from the late first trimester onwards have a tolerizing effect on the maternal adaptive immune response that potentiates successful pregnancies, although this is not yet proven, and no in vivo experiments have been performed. Elevated circulating 


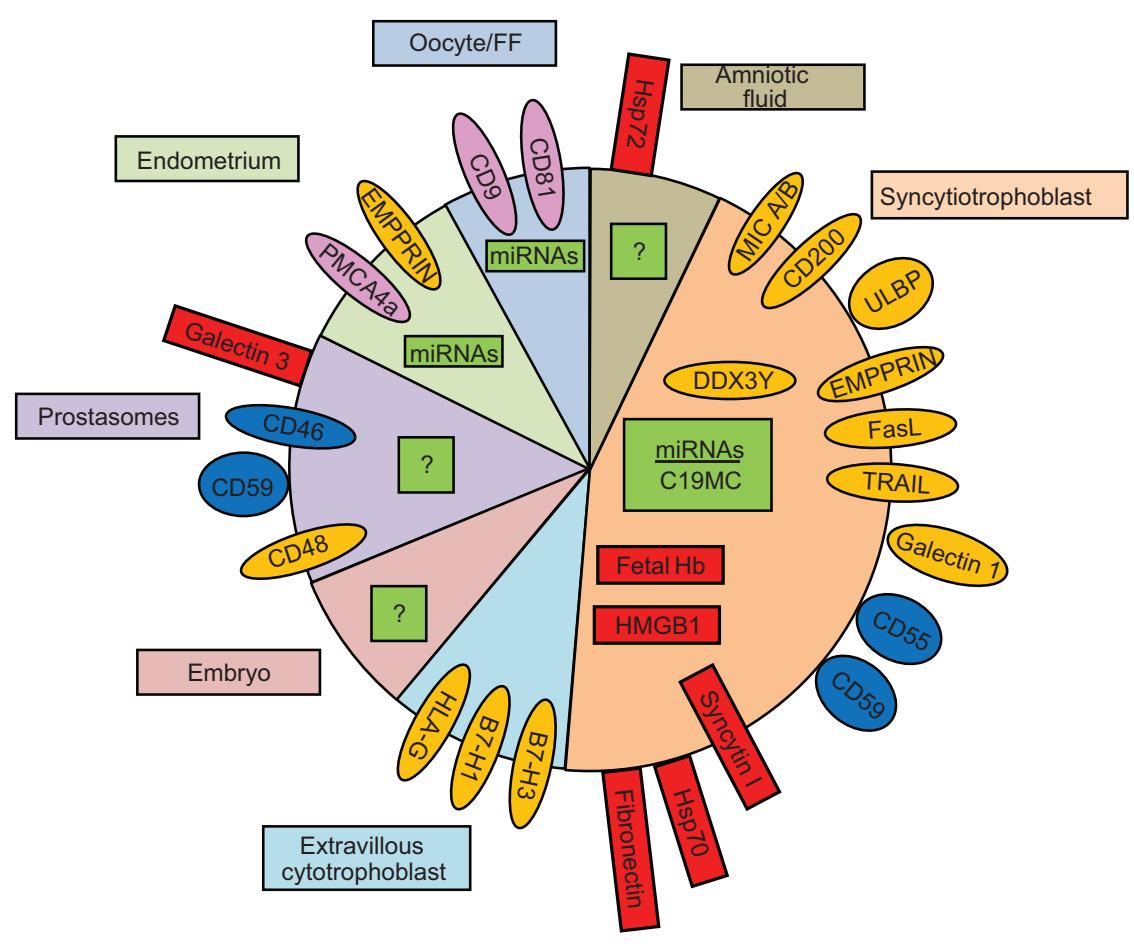

Figure 3 Schematic diagram summarizing various functional moieties carried by reproductive EVs. Proinflammatory mediators (red fill) include HSP70, HSP72, HMGB1, fibronectin, fetal haemoglobin and Syncytin 1. Reproductive EVs have also been shown to contain immunoregulatory molecules (orange fill), with the potential to suppress NK and T cell responses, such as MIC A/B, EMPPRIN, CD200, minor histocompatibility antigen DDX3Y and galectin 1 and complement regulatory proteins (blue fill) CD46, CD55 and CD59. Finally, follicular fluid, endometrial and STB EVs contain miRNAs (green fill) with the potential to further modulate recipient cell responses. HMGB1, high mobility group box 1; MIC A/B, MHC class I chain-related proteins A and B; miRNA, micro-interfering RNA; MV, microvesicle; NK, natural killer; STB, syncytiotrophoblast.

levels in PE are also implicated in contributing to exacerbated maternal systemic innate immune cell activation and vascular dysfunction in PE. Therefore, measurement of STB EVs in the maternal circulation could assist with the detection and management of PE. Biomarkers currently being investigated include sFlt-1, endoglin and PLGF, ${ }^{122,123}$ but as STB EVs contain thousands of proteins, many of which are unique to PE, novel and improved biomarkers could also be discovered. Further understanding of STB EVs in normal pregnancy and PE may also lead to new therapeutic options for women suffering from PE such as neutralizing specific pathogenic EVs, or removal of STB EVs through apheresis. Inhibiting maternal inflammation and reducing vascular damage could allow the pregnancy to continue long enough to avoid the need for very early pre-term delivery, removing the associated risks to both the baby and mother.

This is an exciting time for reproductive EV research. With ongoing improvements to isolation methods, discovery of better markers of EV subtypes and the development of more sensitive techniques to aid detection and characterisation of EVs, further advances will continue to be made in the field. In addition to this, more appropriate models, reflecting the in vivo cellular environment into which the reproductive EVs are released and will function, will be developed to better test their biological effects. With increasing understanding of reproductive EV function comes the great potential for the use of reproductive EVs as biomarkers and therapeutic targets in disorders of both male and female reproduction as well as obstetrics.

\section{ACKNOWLEDGEMENTS}

This work was supported by a MRC Programme Grant (MR/J003360/ 1), the Oxfordshire Health Services Research Committee (OHSRC) Charitable Fund number 8234 (grant OHSRC 1085) and by the Oxford Partnership Comprehensive Biomedical Research Centre (http://www.oxfordbrc.org) with funding from the Department of Health's National Institute for Health Research Biomedical Research Centres funding scheme. The views expressed in this publication are those of the authors and not necessarily those of the Department of Health.

1 Aalberts M, Stout TA, Stoorvogel W. Prostasomes: extracellular vesicles from the prostate. Reproduction 2014; 147: R1-R14.

2 Fest S, Aldo PB, Abrahams VM, Visintin I, Alvero A, Chen R et al. Trophoblast-macrophage interactions: a regulatory network for the protection of pregnancy. Am J Reprod Immunol 2007; 57: 55-66.

3 Apps R, Murphy SP, Fernando R, Gardner L, Ahad T, Moffett A. Human leucocyte antigen (HLA) expression of primary trophoblast cells and placental cell lines, determined using single antigen beads to characterize allotype specificities of anti-HLA antibodies. Immunology 2009; 127: 26-39.

4 Thery C, Ostrowski M, Segura E. Membrane vesicles as conveyors of immune responses. Nat Rev Immunol 2009; 9: 581-593.

5 Redman CW, Sargent IL. Microparticles and immunomodulation in pregnancy and pre-eclampsia. J Reprod Immunol 2007; 76: 61-7. 
6 Valadi H, Ekstrom K, Bossios A, Sjostrand M, Lee JJ, Lotvall JO. Exosome-mediated transfer of mRNAs and microRNAs is a novel mechanism of genetic exchange between cells. Nat Cell Biol 2007; 9: 654-659.

7 Chen X, Liang H, Zhang J, Zen K, Zhang CY. Horizontal transfer of microRNAs: molecular mechanisms and clinical applications. Protein Cell 2012; 3: 28-37.

8 Mouillet JF, Chu T, Sadovsky Y. Expression patterns of placental microRNAs. Birth Defects Res A Clin Mol Teratol 2011; 91: 737743.

9 Liang Y, Ridzon D, Wong L, Chen C. Characterization of microRNA expression profiles in normal human tissues. BMC Genomics 2007; 8: 166.

10 Zhu XM, Han T, Sargent IL, Yin GW, Yao YQ. Differential expression profile of microRNAs in human placentas from preeclamptic pregnancies vs normal pregnancies. Am J Obstet Gynecol 2009; 200: 661 e1-e7.

11 Miura K, Miura S, Yamasaki K, Higashijima A, Kinoshita A, Yoshiura $\mathrm{K}$ et al. Identification of pregnancy-associated microRNAs in maternal plasma. Clin Chem 2010; 56: 1767-1771.

12 Morales Prieto DM, Markert UR. MicroRNAs in pregnancy. J Reprod Immunol 2011; 88: 106-111.

13 Luo SS, Ishibashi O, Ishikawa G, Ishikawa T, Katayama A, Mishima T et al. Human villous trophoblasts express and secrete placentaspecific microRNAs into maternal circulation via exosomes. Biol Reprod 2009; 81: 717-729.

14 Donker RB, Mouillet JF, Chu T, Hubel CA, Stolz DB, Morelli AE et al. The expression profile of C19MC microRNAs in primary human trophoblast cells and exosomes. Mol Hum Reprod 2012; 18: 417424.

15 Noguer-Dance M, Abu-Amero S, Al-Khtib M, Lefevre A, Coullin P, Moore GE et al. The primate-specific microRNA gene cluster (C19MC) is imprinted in the placenta. Hum Mol Genet 2010; 19: 3566-3582.

16 Bullerdiek J, Flor I. Exosome-delivered microRNAs of "chromosome 19 microRNA cluster" as immunomodulators in pregnancy and tumorigenesis. Mol Cytogenet 2012; 5: 27.

17 Raposo G, Stoorvogel W. Extracellular vesicles: exosomes, microvesicles, and friends. J Cell Biol 2013; 200: 373-383.

18 Redman CWG, Tannetta DS, Dragovic RA, Gardiner C, Southcombe $\mathrm{JH}$, Collett GP et al. Review: Does size matter? Placental debris and the pathophysiology of pre- eclampsia. Placenta 2012; 33: S48S54.

19 Chamley LW, Holland OJ, Chen Q, Viall CA, Stone PR, Abumaree M. Review: where is the maternofetal interface? Placenta 2014; 35(Suppl): S74-S80.

20 Cronqvist T, Salje K, Familari M, Guller S, Schneider H, Gardiner C et al. Syncytiotrophoblast vesicles show altered micro-RNA and haemoglobin content after ex-vivo perfusion of placentas with haemoglobin to mimic preeclampsia. PLoS ONE 2014; 9: e90020.

21 Chamley LW, Chen Q, Ding J, Stone PR, Abumaree M. Trophoblast deportation: just a waste disposal system or antigen sharing? J Reprod Immunol 2011; 88: 99-105.

22 Abumaree MH, Chamley LW, Badri M, El-Muzaini MF. Trophoblast debris modulates the expression of immune proteins in macrophages: a key to maternal tolerance of the fetal allograft? J Reprod Immunol 2012; 94: 131-141.

23 Hedlund M, Stenqvist AC, Nagaeva O, Kjellberg L, Wulff M, Baranov $\checkmark$ et al. Human placenta expresses and secretes NKG2D ligands via exosomes that down-modulate the cognate receptor expression: evidence for immunosuppressive function. J Immunol 2009; 183: 340-351.

24 van der Pol E, Coumans F, Varga Z, Krumrey M, Nieuwland R. Innovation in detection of microparticles and exosomes. J Thromb Haemost 2013; 11(Suppl 1): 36-45.

25 van der Pol E, Hoekstra AG, Sturk A, Otto C, van Leeuwen TG, Nieuwland R. Optical and non-optical methods for detection and characterization of microparticles and exosomes. J Thromb Haemost 2010; 8: 2596-2607.
26 Witwer KW, Buzas El, Bemis LT, Bora A, Lasser C, Lotvall J et al. Standardization of sample collection, isolation and analysis methods in extracellular vesicle research. J Extracell Vesicles 2013; 2.

27 Ayers L, Kohler M, Harrison P, Sargent I, Dragovic R, Schaap M et al. Measurement of circulating cell-derived microparticles by flow cytometry: sources of variability within the assay. Thromb Res 2011; 127: 370-377.

28 Lacroix R, Robert S, Poncelet P, Kasthuri RS, Key NS, Dignat-George F. Standardization of platelet-derived microparticle enumeration by flow cytometry with calibrated beads: results of the International Society on Thrombosis and Haemostasis SSC Collaborative Workshop. J Thromb Haemost 2010; 8: 2571-2574.

29 Dragovic RA, Southcombe JH, Tannetta DS, Redman CW, Sargent IL. Multicolor flow cytometry and nanoparticle tracking analysis of extracellular vesicles in the plasma of normal pregnant and preeclamptic women. Biol Reprod 2013; 89: 151.

30 Perez-Pujol S, Marker PH, Key NS. Platelet microparticles are heterogeneous and highly dependent on the activation mechanism: studies using a new digital flow cytometer. Cytometry A 2007; 71: 38-45.

31 Tannetta DS, Dragovic RA, Gardiner C, Redman CW, Sargent IL. Characterisation of syncytiotrophoblast vesicles in normal pregnancy and pre-eclampsia: expression of Flt-1 and endoglin. PLOS ONE 2013; 8: e56754.

32 Nolte-'t Hoen EN, van der Vlist EJ, Aalberts M, Mertens HC, Bosch BJ, Bartelink W et al. Quantitative and qualitative flow cytometric analysis of nanosized cell-derived membrane vesicles. Nanomedicine 2012; 8: 712-720.

33 van der Vlist EJ, Nolte-'t Hoen EN, Stoorvogel W, Arkesteijn GJ, Wauben $\mathrm{MH}$. Fluorescent labeling of nano-sized vesicles released by cells and subsequent quantitative and qualitative analysis by high-resolution flow cytometry. Nat Protoc 2012; 7: 1311-1326.

34 Montoro-Garcia S, Shantsila E, Orenes-Pinero E, Lozano ML, Lip GY. An innovative flow cytometric approach for small-size platelet microparticles: influence of calcium. Thromb Haemost 2012; 108: 373-383.

35 Lok CA, van der Post JA, Sargent IL, Hau CM, Sturk A, Boer K et al. Changes in microparticle numbers and cellular origin during pregnancy and preeclampsia. Hypertens Pregnancy 2008; 27: 344-360.

36 Dragovic RA, Gardiner C, Brooks AS, Tannetta DS, Ferguson DJ, Hole $P$ et al. Sizing and phenotyping of cellular vesicles using Nanoparticle Tracking Analysis. Nanomedicine 2011; 7: 780-788.

37 Kaji K, Oda S, Shikano T, Ohnuki T, Uematsu Y, Sakagami J et al. The gamete fusion process is defective in eggs of $\mathrm{Cd} 9$-deficient mice. Nat Genet 2000; 24: 279-282.

38 Miyado K, Yamada G, Yamada S, Hasuwa H, Nakamura Y, Ryu F et al. Requirement of CD9 on the egg plasma membrane for fertilization. Science 2000; 287: 321-324.

39 Barraud-Lange V, Chalas Boissonnas C, Serres C, Auer J, Schmitt A, Lefevre $B$ et al. Membrane transfer from oocyte to sperm occurs in two CD9-independent ways that do not supply the fertilising ability of Cd9-deleted oocytes. Reproduction 2012; 144: 53-66.

40 Gupta S, Primakoff P, Myles DG. Can the presence of wild-type oocytes during insemination rescue the fusion defect of CD9 null oocytes? Mol Reprod Dev 2009; 76: 602.

41 Miyado K, Yoshida K, Yamagata K, Sakakibara K, Okabe M, Wang X et al. The fusing ability of sperm is bestowed by CD9-containing vesicles released from eggs in mice. Proc Natl Acad Sci USA 2008; 105: 12921-12926.

42 Rubinstein E, Ziyyat A, Prenant M, Wrobel E, Wolf JP, Levy S et al. Reduced fertility of female mice lacking CD81. Dev Biol 2006; 290: 351-358.

43 Tanigawa M, Miyamoto K, Kobayashi S, Sato M, Akutsu H, Okabe M et al. Possible involvement of CD81 in acrosome reaction of sperm in mice. Mol Reprod Dev 2008; 75: 150-155.

44 Ohnami N, Nakamura A, Miyado M, Sato M, Kawano N, Yoshida K et al. CD81 and CD9 work independently as extracellular 
components upon fusion of sperm and oocyte. Biol Open 2012; 1: 640-647.

45 Revelli A, Delle Piane L, Casano S, Molinari E, Massobrio M, Rinaudo P. Follicular fluid content and oocyte quality: from single biochemical markers to metabolomics. Reprod Biol Endocrinol 2009; 7: 40.

46 da Silveira JC, Veeramachaneni DN, Winger QA, Carnevale EM, Bouma GJ. Cell-secreted vesicles in equine ovarian follicular fluid contain miRNAs and proteins: a possible new form of cell communication within the ovarian follicle. Biol Reprod 2012; 86: 71.

47 Diez-Fraile A, Lammens T, Tilleman K, Witkowski W, Verhasselt B, de Sutter $\mathrm{P}$ et al. Age-associated differential microRNA levels in human follicular fluid reveal pathways potentially determining fertility and success of in vitro fertilization. Hum Fertil (Camb) 2014; in press.

48 Sang Q, Yao Z, Wang H, Feng R, Zhao X, Xing Q et al. Identification of microRNAs in human follicular fluid: characterization of microRNAs that govern steroidogenesis in vitro and are associated with polycystic ovary syndrome in vivo. J Clin Endocrinol Metab 2013; 98: 3068-3079.

49 Sohel MM, Hoelker M, Noferesti SS, Salilew-Wondim D, Tholen E, Looft $\mathrm{C}$ et al. Exosomal and non-exosomal transport of extra-cellular microRNAs in follicular fluid: implications for bovine oocyte developmental competence. PLOS ONE 2013; 8: e78505.

50 Al-Dossary AA, Strehler EE, Martin-Deleon PA. Expression and secretion of plasma membrane $\mathrm{Ca}^{2+}$-ATPase 4a (PMCA4a) during murine estrus: association with oviductal exosomes and uptake in sperm. PLOS ONE 2013; 8: e80181.

$51 \mathrm{Ng} \mathrm{YH}$, Rome S, Jalabert A, Forterre A, Singh H, Hincks CL et al. Endometrial exosomes/microvesicles in the uterine microenvironment: a new paradigm for embryo-endometrial cross talk at implantation. PLOS ONE 2013; 8: e58502.

52 Braundmeier AG, Dayger CA, Mehrotra P, Belton RJ Jr, Nowak RA. EMMPRIN is secreted by human uterine epithelial cells in microvesicles and stimulates metalloproteinase production by human uterine fibroblast cells. Reprod Sci 2012; 19: 1292-301.

53 Burnett LA, Light MM, Mehrotra P, Nowak RA. Stimulation of GPR30 increases release of EMMPRIN-containing microvesicles in human uterine epithelial cells. J Clin Endocrinol Metab 2012; 97: 4613-4622.

54 Ronquist G. Prostasomes are mediators of intercellular communication: from basic research to clinical implications. $J$ Intern Med 2012; 271: 400-413.

55 Skibinski G, Kelly RW, Harkiss D, James K. Immunosuppression by human seminal plasma-extracellular organelles (prostasomes) modulate activity of phagocytic cells. Am J Reprod Immunol 1992; 28: 97-103.

56 Tarazona R, Delgado E, Guarnizo MC, Roncero RG, Morgado S, Sanchez-Correa B et al. Human prostasomes express CD48 and interfere with NK cell function. Immunobiology 2011; 216: 41-46.

57 Kitamura M, Namiki M, Matsumiya K, Tanaka K, Matsumoto M, Hara T et al. Membrane cofactor protein (CD46) in seminal plasma is a prostasome-bound form with complement regulatory activity and measles virus neutralizing activity. Immunology 1995; 84: 626-632.

58 Rooney IA, Atkinson JP, Krul ES, Schonfeld G, Polakoski K, Saffitz $\mathrm{JE}$ et al. Physiologic relevance of the membrane attack complex inhibitory protein CD59 in human seminal plasma: CD59 is present on extracellular organelles (prostasomes), binds cell membranes, and inhibits complement-mediated lysis. J Exp Med 1993; 177: 1409-1420.

59 Saez F, Motta C, Boucher D, Grizard G. Antioxidant capacity of prostasomes in human semen. Mol Hum Reprod 1998; 4: 667-672.

60 Jones JL, Saraswati S, Block AS, Lichti CF, Mahadevan M, Diekman AB. Galectin-3 is associated with prostasomes in human semen. Glycoconj J 2010; 27: 227-236.

61 Harris LK. IFPA Gabor than Award lecture: transformation of the spiral arteries in human pregnancy: key events in the remodelling timeline. Placenta 2011; 32: S154-S158.
62 Red-Horse K, Zhou Y, Genbacev O, Prakobphol A, Foulk R, McMaster $\mathrm{M}$ et al. Trophoblast differentiation during embryo implantation and formation of the maternal-fetal interface. J Clin Invest 2004; 114: 744-754.

63 Knofler M, Pollheimer J. IFPA Award in Placentology Lecture: molecular regulation of human trophoblast invasion. Placenta 2012; 33: S55-S62.

64 Burton GJ, Jauniaux E, Charnock-Jones DS. Human early placental development: potential roles of the endometrial glands. Placenta 2007; 28(Suppl A): S64-S69.

65 Sargent IL, Borzychowski AM, Redman CW. NK cells and human pregnancy-an inflammatory view. Trends Immunol 2006; 27: 399-404.

66 Kshirsagar SK, Alam SM, Jasti S, Hodes H, Nauser T, Gilliam M et al. Immunomodulatory molecules are released from the first trimester and term placenta via exosomes. Placenta 2012; 33: 982-990.

67 Orozco AF, Jorgez CJ, Ramos-Perez WD, Popek EJ, Yu X, Kozinetz CA et al. Placental release of distinct DNA-associated micro-particles into maternal circulation: reflective of gestation time and preeclampsia. Placenta 2009; 30: 891-897.

68 Pap E, Pallinger E, Falus A, Kiss AA, Kittel A, Kovacs P et al. T lymphocytes are targets for platelet- and trophoblast-derived microvesicles during pregnancy. Placenta 2008; 29: 826-832.

69 Sargent I, Dragovic RA, Tannetta D, Redman C, Extracellular vesicles in normal pregnancy and pre-eclampsia. In: Extracellular Vesicles in Health and Disease. Oxford: Pan Stanford Publishing, 2014; 357-390

70 Atay S, Gercel-Taylor C, Kesimer M, Taylor DD. Morphologic and proteomic characterization of exosomes released by cultured extravillous trophoblast cells. Exp Cell Res 2011; 317: 11921202.

71 Gonen-Gross T, Achdout H, Arnon TI, Gazit R, Stern N, Horejsi V et al. The CD85J/leukocyte inhibitory receptor-1 distinguishes between conformed and beta 2-microglobulin-free HLA-G molecules. J Immunol 2005; 175: 4866-4874.

72 Bainbridge DR, Ellis SA, Sargent IL. HLA-G suppresses proliferation of CD4 ${ }^{+}$T-lymphocytes. J Reprod Immunol 2000; 48: 17-26.

73 Atay S, Gercel-Taylor C, Suttles J, Mor G, Taylor DD. Trophoblastderived exosomes mediate monocyte recruitment and differentiation. Am J Reprod Immunol 2011; 65: 65-77.

74 Atay S, Gercel-Taylor C, Taylor DD. Human trophoblast-derived exosomal fibronectin induces pro-inflammatory IL-1beta production by macrophages. Am J Reprod Immunol 2011; 66: 259-269.

75 Burton GJ, Sebire NJ, Myatt L, Tannetta D, Wang YL, Sadovsky Y et al. Optimising sample collection for placental research. Placenta 2014; 35: 9-22.

76 Burton GJ, Jones CJ. Syncytial knots, sprouts, apoptosis, and trophoblast deportation from the human placenta. Taiwan J Obstet Gynecol 2009; 48: 28-37.

77 Knight M, Redman CW, Linton EA, Sargent IL. Shedding of syncytiotrophoblast microvilli into the maternal circulation in preeclamptic pregnancies. Br J Obstet Gynaecol 1998; 105: 632-640.

78 Germain SJ, Sacks GP, Sooranna SR, Sargent IL, Redman CW. Systemic inflammatory priming in normal pregnancy and preeclampsia: the role of circulating syncytiotrophoblast microparticles. J Immunol 2007; 178: 5949-5956.

79 Reddy A, Zhong XY, Rusterholz C, Hahn S, Holzgreve W, Redman CW et al. The effect of labour and placental separation on the shedding of syncytiotrophoblast microparticles, cell-free DNA and mRNA in normal pregnancy and pre-eclampsia. Placenta 2008; 29: 942949.

80 Sabapatha A, Gercel-Taylor C, Taylor DD. Specific isolation of placenta-derived exosomes from the circulation of pregnant women and their immunoregulatory consequences. Am J Reprod Immunol 2006; 56: 345-355.

81 Johansen M, Redman CW, Wilkins T, Sargent IL. Trophoblast deportation in human pregnancy-its relevance for pre-eclampsia. Placenta 1999; 20: 531-539. 
82 Takahashi Y, Nishikawa M, Shinotsuka H, Matsui Y, Ohara S, Imai T et al. Visualization and in vivo tracking of the exosomes of murine melanoma B16-BL6 cells in mice after intravenous injection. J Biotechnol 2013; 165: 77-84.

83 Southcombe J, Tannetta D, Redman C, Sargent I. The immunomodulatory role of syncytiotrophoblast microvesicles. PLOS ONE 2011; 6: e20245.

84 Holland OJ, Linscheid C, Hodes HC, Nauser TL, Gilliam M, Stone P et al. Minor histocompatibility antigens are expressed in syncytiotrophoblast and trophoblast debris: implications for maternal alloreactivity to the fetus. Am J Pathol 2012; 180: 256266.

85 Mincheva-Nilsson L, Nagaeva O, Chen T, Stendahl U, Antsiferova J, Mogren I et al. Placenta-derived soluble MHC class I chain-related molecules down-regulate NKG2D receptor on peripheral blood mononuclear cells during human pregnancy: a possible novel immune escape mechanism for fetal survival. J Immunol 2006; 176: 3585-3592.

86 Thibault G, Degenne D, Girard AC, Guillaumin JM, Lacord M, Bardos $P$. The inhibitory effect of human syncytiotrophoblast plasma membrane vesicles on in vitro lymphocyte proliferation is associated with reduced interleukin 2 receptor expression. Cell Immunol 1991; 138: 165-174.

87 Arkwright PD, Rademacher TW, Boutignon F, Dwek RA, Redman CW. Suppression of allogeneic reactivity in vitro by the syncytiotrophoblast membrane glycocalyx of the human term placenta is carbohydrate dependent. Glycobiology 1994; 4: 39-47.

88 Gupta AK, Rusterholz C, Holzgreve W, Hahn S. Syncytiotrophoblast micro-particles do not induce apoptosis in peripheral T lymphocytes, but differ in their activity depending on the mode of preparation. J Reprod Immunol 2005; 68: 15-26.

89 Taylor DD, Akyol S, Gercel-Taylor C. Pregnancy-associated exosomes and their modulation of T cell signaling. J Immunol 2006; 176: 1534-1542.

90 Stenqvist AC, Nagaeva O, Baranov V, Mincheva-Nilsson L. Exosomes secreted by human placenta carry functional Fas ligand and TRAIL molecules and convey apoptosis in activated immune cells, suggesting exosome-mediated immune privilege of the fetus. J Immunol 2013; 191: 5515-5523.

91 Abumaree MH, Stone PR, Chamley LW. The effects of apoptotic, deported human placental trophoblast on macrophages: possible consequences for pregnancy. J Reprod Immunol 2006; 72: 33-45.

92 Sacks GP, Studena K, Sargent K, Redman CW. Normal pregnancy and preeclampsia both produce inflammatory changes in peripheral blood leukocytes akin to those of sepsis. Am J Obstet Gynecol 1998; 179: 80-86.

93 Messerli M, May K, Hansson SR, Schneider H, Holzgreve W, Hahn S et al. Feto- maternal interactions in pregnancies: placental microparticles activate peripheral blood monocytes. Placenta 2010; 31: 106-112.

94 Aly AS, Khandelwal M, Zhao J, Mehmet AH, Sammel MD, Parry S. Neutrophils are stimulated by syncytiotrophoblast microvillous membranes to generate superoxide radicals in women with preeclampsia. Am J Obstet Gynecol 2004; 190: 252-258.

95 Gupta AK, Hasler P, Holzgreve W, Gebhardt S, Hahn S. Induction of neutrophil extracellular DNA lattices by placental microparticles and IL-8 and their presence in preeclampsia. Hum Immunol 2005; 66: 1146-1154.

96 Redman CW, Tannetta DS, Dragovic RA, Gardiner C, Southcombe $\mathrm{JH}$, Collett GP et al. Review: Does size matter? Placental debris and the pathophysiology of pre-eclampsia. Placenta 2012; 33(Suppl): S48-S54.

97 Delorme-Axford E, Donker RB, Mouillet JF, Chu T, Bayer A, Ouyang Y et al. Human placental trophoblasts confer viral resistance to recipient cells. Proc Natl Acad Sci U S A 2013; 110: 1204812053.

98 Keller S, Rupp C, Stoeck A, Runz S, Fogel M, Lugert S et al. CD24 is a marker of exosomes secreted into urine and amniotic fluid. Kidney Int 2007; 72: 1095-1102.
99 Asea A, Jean-Pierre C, Kaur P, Rao P, Linhares IM, Skupski D et al. Heat shock protein-containing exosomes in mid-trimester amniotic fluids. J Reprod Immunol 2008; 79: 12-17.

100 Bretz NP, Ridinger J, Rupp AK, Rimbach K, Keller S, Rupp C et al. Body fluid exosomes promote secretion of inflammatory cytokines in monocytic cells via Toll-like receptor signaling. J Biol Chem 2013; 288: 36691-36702.

101 Francavilla F, Santucci R, Barbonetti A, Francavilla S. Naturallyoccurring antisperm antibodies in men: interference with fertility and clinical implications. An update. Front Biosci 2007; 12: 2890-2911.

102 Allegrucci C, Ronquist G, Ove Nilsson B, Carlsson L, Lundqvist M, Minelli $A$ et al. Circulating human antisperm antibodies recognize prostasomes. Am J Reprod Immunol 2001; 46: 211-219.

103 Carlsson L, Ronquist G, Nilsson BO, Larsson A. Dominant prostasome immunogens for sperm-agglutinating autoantibodies of infertile men. J Androl 2004; 25: 699-705.

104 Tavoosidana G, Ronquist G, Darmanis S, Yan J, Carlsson L, Wu D et al. Multiple recognition assay reveals prostasomes as promising plasma biomarkers for prostate cancer. Proc Natl Acad Sci USA 2011; 108: 8809-8814.

105 Tannetta D, Sargent I. Placental disease and the maternal syndrome of preeclampsia: missing links? Curr Hypertens Rep 2013; 15 : 590-599.

106 Burton GJ, Jauniaux E. Placental oxidative stress: from miscarriage to preeclampsia. J Soc Gynecol Investig 2004; 11: 342-52.

107 Redman CW, Sargent IL. Latest advances in understanding preeclampsia. Science 2005; 308: 1592-4.

108 Goswami D, Tannetta DS, Magee LA, Fuchisawa A, Redman CW, Sargent IL et al. Excess syncytiotrophoblast microparticle shedding is a feature of early-onset pre-eclampsia, but not normotensive intrauterine growth restriction. Placenta 2006; 27: 56-61.

109 Chen Y, Huang Y, Jiang R, Teng Y. Syncytiotrophoblast-derived microparticle shedding in early-onset and late-onset severe preeclampsia. Int J Gynaecol Obstet 2012; 119: 234-238.

110 Marques F, Campos FM, Filho OA, Carvalho AT, Dusse LM, Gomes KB. Circulating microparticles in severe preeclampsia. Clin Chim Acta 2012; 414: 253-258.

111 Redman CW. Preeclampsia: a multi-stress disorder. Rev Med Interne 2011; 32(Suppl 1): S41-S44.

112 Holder BS, Tower CL, Jones CJ, Aplin JD, Abrahams VM. Heightened pro-inflammatory effect of preeclamptic placental microvesicles on peripheral blood immune cells in humans. Biol Reprod 2012; 86: 103.

113 Cester N, Staffolani R, Rabini RA, Magnanelli R, Salvolini E, Galassi $\mathrm{R}$ et al. Pregnancy induced hypertension: a role for peroxidation in microvillus plasma membranes. Mol Cell Biochem 1994; 131: 151-155.

114 Macey MG, Bevan S, Alam S, Verghese L, Agrawal S, Beski S et al. Platelet activation and endogenous thrombin potential in preeclampsia. Thromb Res 2010; 125: e76-e81.

115 Gardiner C, Tannetta DS, Simms CA, Harrison P, Redman CW, Sargent IL. Syncytiotrophoblast microvesicles released from preeclampsia placentae exhibit increased tissue factor activity. PLOS ONE 2011; 6: e26313.

116 Reverdiau P, Jarousseau AC, Thibault G, Khalfoun B, Watier H, Lebranchu $Y$ et al. Tissue factor activity of syncytiotrophoblast plasma membranes and tumoral trophoblast cells in culture. Thromb Haemost 1995; 73: 49-54.

117 Smarason AK, Sargent IL, Starkey PM, Redman CW. The effect of placental syncytiotrophoblast microvillous membranes from normal and pre-eclamptic women on the growth of endothelial cells in vitro. Br J Obstet Gynaecol 1993; 100: 943-949.

118 Gupta AK, Rusterholz C, Huppertz B, Malek A, Schneider H, Holzgreve $W$ et al. A comparative study of the effect of three different syncytiotrophoblast micro-particles preparations on endothelial cells. Placenta 2005; 26: 59-66.

119 Hoegh AM, Tannetta D, Sargent I, Borup R, Nielsen FC, Redman C et al. Effect of syncytiotrophoblast microvillous membrane treatment on gene expression in human umbilical vein endothelial cells. Br J Obstet Gynaecol 2006; 113: 1270-1279. 
120 Cockell AP, Learmont JG, Smarason AK, Redman CW, Sargent IL, Poston L. Human placental syncytiotrophoblast microvillous membranes impair maternal vascular endothelial function. $\mathrm{Br} \mathrm{J}$ Obstet Gynaecol 1997; 104: 235-240.

121 von Dadelszen P, Hurst G, Redman CW. Supernatants from cocultured endothelial cells and syncytiotrophoblast microvillous membranes activate peripheral blood leukocytes in vitro. Hum Reprod 1999; 14: 919-924.

122 Blumenstein M, McMaster MT, Black MA, Wu S, Prakash R, Cooney $\mathrm{J}$ et al. A proteomic approach identifies early pregnancy biomarkers for preeclampsia: novel linkages between a predisposition to preeclampsia and cardiovascular disease. Proteomics 2009; 9: 2929-2945.
123 Rasanen J, Girsen A, Lu X, Lapidus JA, Standley M, Reddy A et al. Comprehensive maternal serum proteomic profiles of preclinical and clinical preeclampsia. J Proteome Res 2010; 9: 4274-4281.

\section{(c) (1)()(-) This work is licensed under a Creative Commons}

Attribution-NonCommercial-ShareAlike 3.0 Unported

License. The images or other third party material in this article are included in the article's Creative Commons license, unless indicated otherwise in the credit line; if the material is not included under the Creative Commons license, users will need to obtain permission from the license holder to reproduce the material. To view a copy of this license, visit http://creativecommons.org/licenses/by-nc-sa/3.0/ 